\title{
Pharmaceutical regulations in Iraq: from medicine approval to post- marketing
}

Ali Azeez Al-Jumaili, ${ }^{1}$ Manal Mohammed Younus, ${ }^{2}$ Yasmine J. A. Kannan, ${ }^{3}$ Zinah E. Nooruldeen ${ }^{4}$ and Adi Al-Nuseirat ${ }^{5}$

${ }^{1}$ University of Baghdad College of Pharmacy, Baghdad, Iraq. ${ }^{2}$ Ministry of Health, Iraqi Pharmacovigilance Center, Baghdad, Iraq. ${ }^{3}$ Ministry of Health, Minister's Office, Baghdad, Iraq. ${ }^{4}$ Department of Health Systems, World Health Organization Country Office, Baghdad, Iraq. ${ }^{5}$ Department of Health Systems, World Health Organization Regional Office for the Eastern Mediterranean, Cairo, Egypt. (Correspondence to: Ali Azeez Al-Jumaili: ali.baraak@ copharm.uobaghdad.edu.iq).

\begin{abstract}
Background: Recent information on regulation of the pharmaceutical sector in Iraq is scarce.

Aims: This report summarizes the regulations governing pharmaceutical products in Iraq, assesses the challenges faced and makes recommendations to tackle these issues.

Methods: The Iraq pharmaceutical country profile 2020, prepared by the Iraqi Ministry of Health in collaboration with the World Health Organization (WHO) in 2020, was the main source of information.

Results: Despite all the efforts by the Ministry of Health to provide adequate and safe medicines, the Iraqi pharmaceutical sector has several challenges, including inadequate budget allocated to the ministry, shortages in essential medicines, underutilization of electronic technologies in the management of regulation-related work, a large number of substandard and falsified medications in the private sector and a stagnant national pharmaceutical industry.

Conclusion: The Ministry of Health needs more financial support from the federal government to fund its activities and technical support from international health organizations to provide training and resources.

Keywords: drug industry, essential drugs, regulation, Iraq

Citation: Al-Jumaili A; Younus M; Kannan Y; Nooruldeen Z; Al-Nuseirat A. Pharmaceutical regulations in Iraq: from medicine approval to post-marketing. East Mediterr Health J. 2021;27(10):1007-1015. https://doi.org/10.26719/emhj.21.025

Received: 22/10/20; accepted: 10/03/21

Copyright $($ C World Health Organization (WHO) 2021. Some rights reserved. This work is available under the CC BY-NC-SA 3.0 IGO license https:// creativecommons.org/licenses/by-nc-sa/3.o/igo
\end{abstract}

\section{Introduction}

Iraq has suffered several wars in the past 4 decades which resulted in significant humanitarian crises. In 2019, the country had a total population of 39.128 million (1) and a gross domestic product (GDP) of US\$ 110.83 billion (133 trillion Iraqi dinars) (2). However, only 4.5\% (about US\$ 5 billion) of the GDP was allocated to the health care sector. This percentage is low compared with other countries in the Middle East region with comparable GDPs. Government expenditure on pharmaceuticals was US\$ 1.25 billion for all population, which represented $25 \%$ of the total health expenditure (2).

All people are covered by government health services (3). All health care facilities in the public sector are owned by the government and under the authority of the Ministry of Health and Environment (hereafter called the Ministry of Health). All health care providers working in the public health sector are government employees. No accurate data are available on private health insurance as it is not commonly used in Iraq (2).

This report aims to describe the regulation of pharmaceutical products by the Iraqi Ministry of Health from registration and approval to post-marketing, assess the main challenges faced and make recommendations to tackle the issues.

\section{National Regulatory Authority}

Four directorates within the Ministry of Health are involved in regulation of medicines: Directorate of Technical Affairs, the State Company for Marketing Drugs and Medical Appliances (KIMADIA), Directorate of Public Health and Directorate of Inspection. The Directorate of Technical Affairs is the main entity responsible for medicine regulation. This Directorate has several departments: Pharmacy Department, Registrations Department, National Committee for Drug Selection, National Centre for Drug Control and Research, Consulting Committees, Therapeutics Department, Needs Estimation Department, National Committee for Selection of Herbal Medicines and Food Supplements and Herbal Medicines Department (Figure 1) (4).

The Directorate of Technical Affairs has the following functions as the medicinal regulatory authority in Iraq: approving medicines/vaccines, issuing marketing authorization, regulatory inspection, granting import and manufacture licences, laboratory testing (quality control and assurance), controlling release of medicines to the market and pharmacovigilance. The Directorate regulates the following health products: medicines, biotherapeutics, vaccines, blood and blood components, herbal and traditional medicines, food supplements, medical devices, diagnostics and narcotics. 
Figure 1 Hierarchy of regulatory bodies for medicinal products within the Directorate of Technical Affairs, Ministry of Health, Iraq

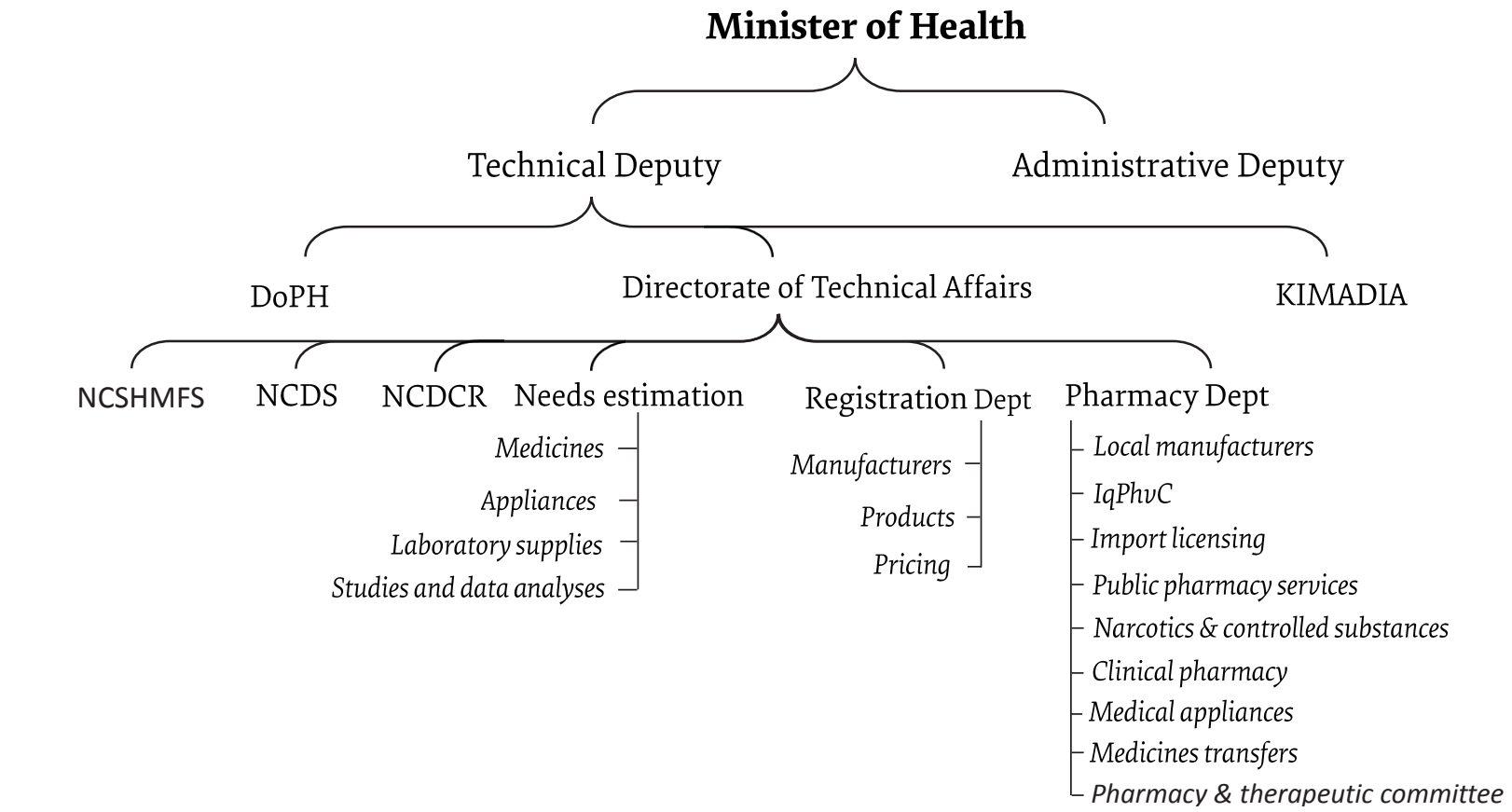

DoPH=Directorate of Public Health; KIMADIA: State Company for Medicine Importation \& Marketing; NCSHMFS=National Committee for Selection of Herbal Medicines and Food Supplements; NCDS=National Committee for Drug Selection; NCDCR=National Centre for Drug Control and Research; IqPhvC=Iraqi Pharmacovigilance Centre.

\section{Approval of medicines}

The National Committee for Drugs Selection is responsible for selecting medicines and vaccines for the national essential medicines list (EML) and comprehensive medicines list (4). The National Committee usually includes 12-16 specialist physicians and pharmacists representing different specialties and departments. The Committee may approve new medications in each meeting and the members usually meet weekly. Hence, medicines in the EML are updated regularly.

The national EML contains medicines and vaccines that need to be available in public health care settings. The EML has three levels (levels 1, 2 and 3) (5). As of 23 June 2020, 1105 medicines and vaccines were included in the EML, but only 554 of them were at level 1 . The three levels refer to the need to secure medicines for public health care settings (hospitals and primary health care centres). The three levels include different medications from each pharmacological group and class. Level 1 medications are the most cost-effective ones. The central public agency for procurement in the health ministry (KIMADIA) is responsible for procuring level 1 medicines on the EML for public health care facilities. Although medicines on levels 2 and 3 of the EML are approved for public facilities, they are not required to be procured by the State Company. However, level 2 and 3 medications can be procured by peripheral public health care facilities, but the priority is for level 2 over level 3 medications. In other words, if medicines on level 1 are not secured by KIMADIA, health care directorates and hospitals can procure level 2 medicines as alternative. If level 2 medicines are not available in the market, then they can procure level 3 medicines instead.

The Comprehensive Medicine List includes additional medicines which can be procured by the private sector. As of June 23, 2020, the Comprehensive Medicine List included 3700 (essential and non-essential) medicines. Some medicines are approved for the comprehensive list, but not for the EML (5).

To select the most cost-effective medications, the National Committee for Drugs Selection requests pharmacoeconomic studies to be conducted by the unit on studies and data analyses at the Needs Estimation Department before approving high-cost medications for the EML, such as biological and oncology medicines (5).

It is worth mentioning that the National Committee for Drugs Selection is not responsible for approving herbal or traditional medicines. The National Committee for Selection of Herbal Medicines and Food Supplements oversees the approval of herbal and natural medicines, and sports and food supplements in the National Herbal List (5).

\section{Registration of pharmaceutical compa- nies and products}

Figure 2 shows the regulatory pathways for registration and approval of pharmaceutical companies and products in the private and public sectors in Iraq.

The Registration Department of the Directorate of Technical Affairs is responsible for registration (marketing authorization) of pharmaceutical companies and medicinal products for both private and public 
Figure 2 Regulatory pathways for medicinal products in private and public sectors, Iraq

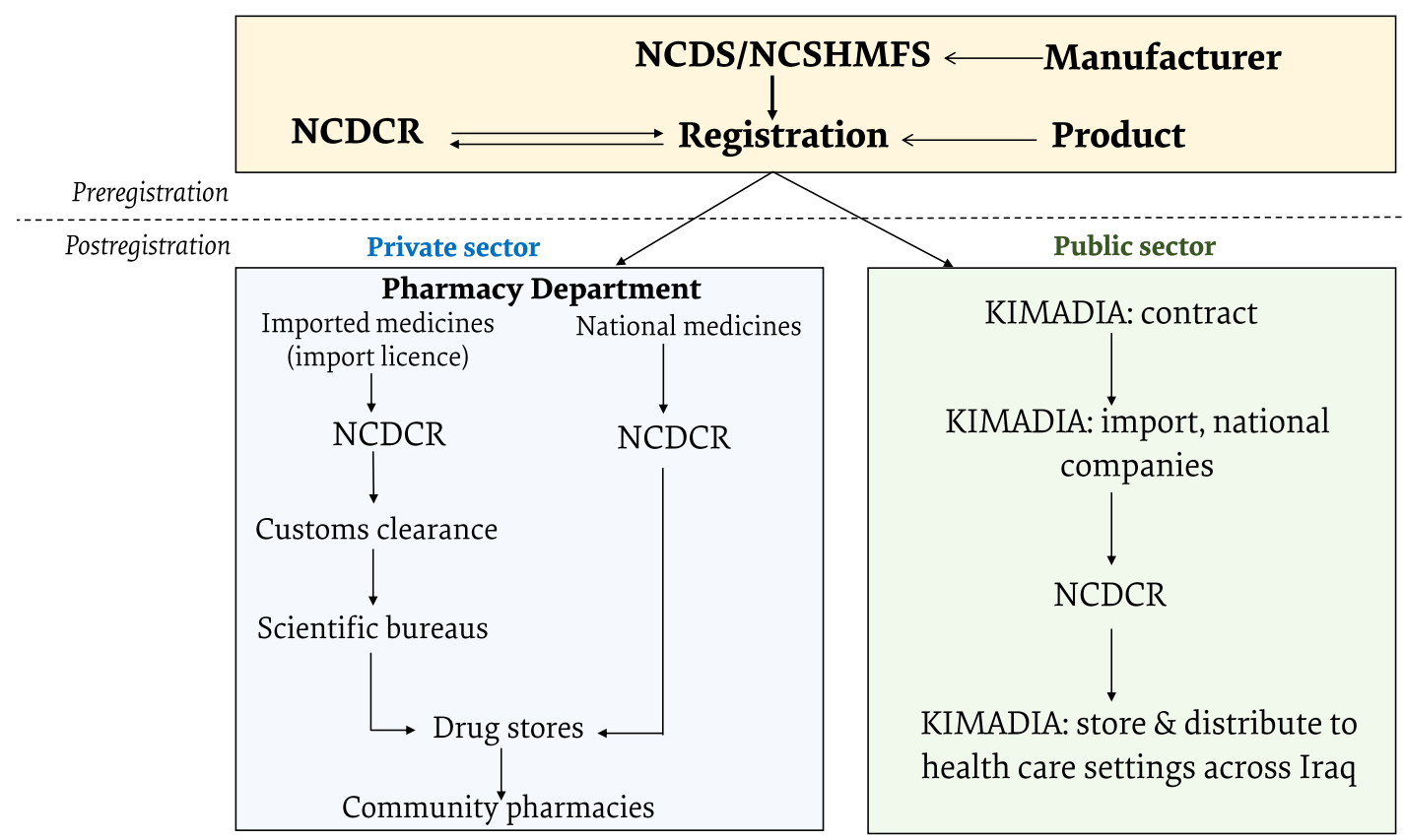

NCDS=National Committee for Drug Selection; NCSHMFS= National Committee for Selection of Herbal Medicines and Food Supplements; NCDCR= National Centre for Drug Control \& Research; KIMADIA: State Company for Medicine Importation \& Marketing.

sectors, whether they are produced nationally or internationally. The Registration Department includes several technical committees and subcommittees: Medicines' Registration Committee, Bioequivalence Study Committee, Biological Medicines Committee, Medical Appliances Committee, Laboratory Materials' Committee, Pharmaceutical Company Registration Committee and Price Determination Committee.

The most important prequalifications to register pharmaceutical companies include a good manufacturing practice (GMP) certificate and a certificate of pharmaceutical product, preferably from one or more of the following medicine regulatory agencies: United States Food and Drug Administration (FDA); European Medicines Agency (EMA); Medicines and Healthcare Products Regulatory Agency, United Kingdom of Great Britain and Northern Ireland; Swiss surveillance authority for medicines (Swissmedic); Health Product and Food Branch, Canada; Therapeutic Goods Administration, Australia; Ministry of Health, Labour and Welfare of Japan; or Gulf Cooperation Council (GCC) (5).

Information on registered medical products, authorized companies and licenced facilities are recorded, reviewed and updated by the Registration Department every 5 years (5). However, this information may not be published routinely. If a scientific bureau or pharmaceutical company fails to update its product information after 5 years of registration, its product registration will be revoked automatically.

International manufacturers that do not have one of the above-mentioned certifications, need to be visited once by a health ministry expert team (from the Pharmacy and Registration Departments) to make sure they follow GMP before being approved as a supplier (5).

\section{Recognized certification}

The Directorate of Technical Affairs recognizes reliable certifications (from FDA, EMA, WHO and the medicines authorities of Australia, Canada, Japan and the United Kingdom) (6). According to regulations of the Directorate of Technical Affairs in February 2018, pharmaceutical companies with products that have one or more of reliable certificate(s) (from EMA, FDA, Swissmedic, or the medicines authorities of Australia, Canada, Japan and the United Kingdom and the GCC) will be exempt from the inspection visit that is usually required before company registration. In addition, pharmaceutical companies that have one of the above-mentioned recognized certificates (e.g. FDA, EMA) are also exempt from batch testing by the National Centre for Drug Control and Research (5). Similarly, the National Committee for Drug Selection recognizes EMA and/or FDA certificates which are the most acceptable criteria on which to base decisions to approve new medicines in the essential or comprehensive medicine lists.

\section{Pharmaceutical products and companies registered in Iraq}

As of 12 August 2020, the Registration Department had 4665 registered medicines and vaccines. The number of registered medicines has increased over the past 3 years from 2500 in December 2018 to 4665 in August 2020. This increase has been achieved by adopting fast track registration and assigning specialized expert registration committees for each type of medicinal product (pharma- 
ceuticals, biologicals, medical appliances or laboratory material producers). The Registration Department implemented the fast track registration in February 2019 to accelerate the registration of urgently needed medications. Fast track registration allows pharmaceutical products that have approval certificates from credible health organizations (FDA, EMA or any of the medicines authorities listed earlier) to have temporary registration and receive and import licence within 1 month. Fast track registration requires seven documents about a newly approved medicine: certificate of pharmaceutical product; characteristics; composition; analytical methods; stability study; price certificate; and samples. However, the regular registration pathway takes about 1 year to process all required documents. The Registration Department has also increased the number of registered pharmaceutical companies from 1481 in December 2018 to 1801 in August 2020 (5).

\section{Determination of medicine prices}

The Registration Department determines the registration price of medicines (5). However, KIMADIA may negotiate companies to lower their price to below the registered prices during their application to win a public procurement tender. On the other hand, the Syndicate of Iraqi Pharmacists uses the registered prices to determine the prices on the registered medication sticker sold to the private sector.

The Registration Department regulations determine the prices of brand medicines according to a national guideline which relies mainly on the prices in some neighbouring counties (Jordan and Saudi Arabia) and in the British National Formulary. On the other hand, determination of the prices of generic medicines depends on the geographical area of the manufacturers. For instance, if the pharmaceutical manufacturers are based in North America, Europe, Australia, South Korea or Japan, the price of generics equals to $60 \%$ of the brand price, given that brand prices may differ between countries. When the manufacturers are based in the Middle East, Arabic countries or South America, the price of generic equals to $40 \%$ of the brand price. Finally, when manufacturers are based in east and south-east Asia (e.g. China, India), the price of generic medicine equals to $20 \%$ of the brand price (5).

Only officially procured medicines in the private sector have price stickers of the Syndicate of Iraqi Pharmacists. It is worth noting that public health care settings provide the prescribed medications to patients at subsidized prices. For example, the fees of any prescription for outpatients at public health clinics are between US\$ 0.8 and US\$ 2.5 only.

\section{Granting marketing licence to pharmaceutical companies}

The Pharmacy Department of the Directorate of Technical Affairs is responsible for granting import licences to international companies and working licences to national manufacturers (Figure 3). Import licences for interna- tional and national companies are valid for 1 year. All international pharmaceutical manufacturers should have a GMP certificate to be registered.

The Syndicate of Iraqi Pharmacists (a nongovernmental organization) has the authority to grant licences to scientific drug bureaus, private wholesalers (drug stores) and private community pharmacies, which are inspected by both the Inspection Directorate of the Ministry of Health and the Syndicate of Iraqi Pharmacists (Figure 3) $(7,8)$.

\section{Regulation of national pharmaceutical manufacturing}

Experts from the National Industry Section at the Pharmacy Department should inspect national pharmaceutical companies before granting a work licence. To obtain a work licence, national pharmaceutical manufacturers need to follow GMP (according to the WHO requirements) (5).

There are 23 national pharmaceutical manufacturers (two governmental and 21 private) in Iraq. They are actual manufacturers and produce the finished products. However, no national factory produces active pharmaceutical ingredients or packages already formulated imported products. Nor do these manufacturers produce biopharmaceuticals or WHO prequalified products. A recent mixed-method study interviewed seven managers or owners of national manufactures to explore the challenges facing these companies (9). They said experienced several financial and regulation difficulties including the lengthy process to get a 1-year import licence, delays in payments from KIMADIA and barriers to importing active ingredients $(5,9)$. As a result, the market share of domestic pharmaceutical medicines was only $15.3 \%$ of the total value of public sector (KIMADIA) contracts in 2019. In terms of volume share, national pharmaceutical products represented $47.8 \%$ of the total volume of public sector medicine contracts in the same year. This indicates that most nationally produced medicines were low cost (5).

\section{Medicine procurement for the public sector}

KIMADIA, founded in 1964, is the agency responsible for procurement and distribution of medicines, medical appliances and equipment for public health care settings (public hospitals and primary health care settings) in all 18 provinces if Iraq (Figure 2). If KIMADIA is unable to secure medicines in the EML, health directorates in all provinces have the right to procure these essential medicines from the private sector (10). In 2019, KIMADIA procured $60 \%$ of essential medicines in the EML (level 1). An insufficient budget allocated to KIMADIA is one of the main reasons for a shortage in essential medicines in Iraq in the past few decades.

\section{Medicine procurement for the private sector}

The private sector medicine procurement and distribution differs from the public sector. Registered international pharmaceutical companies can market their 


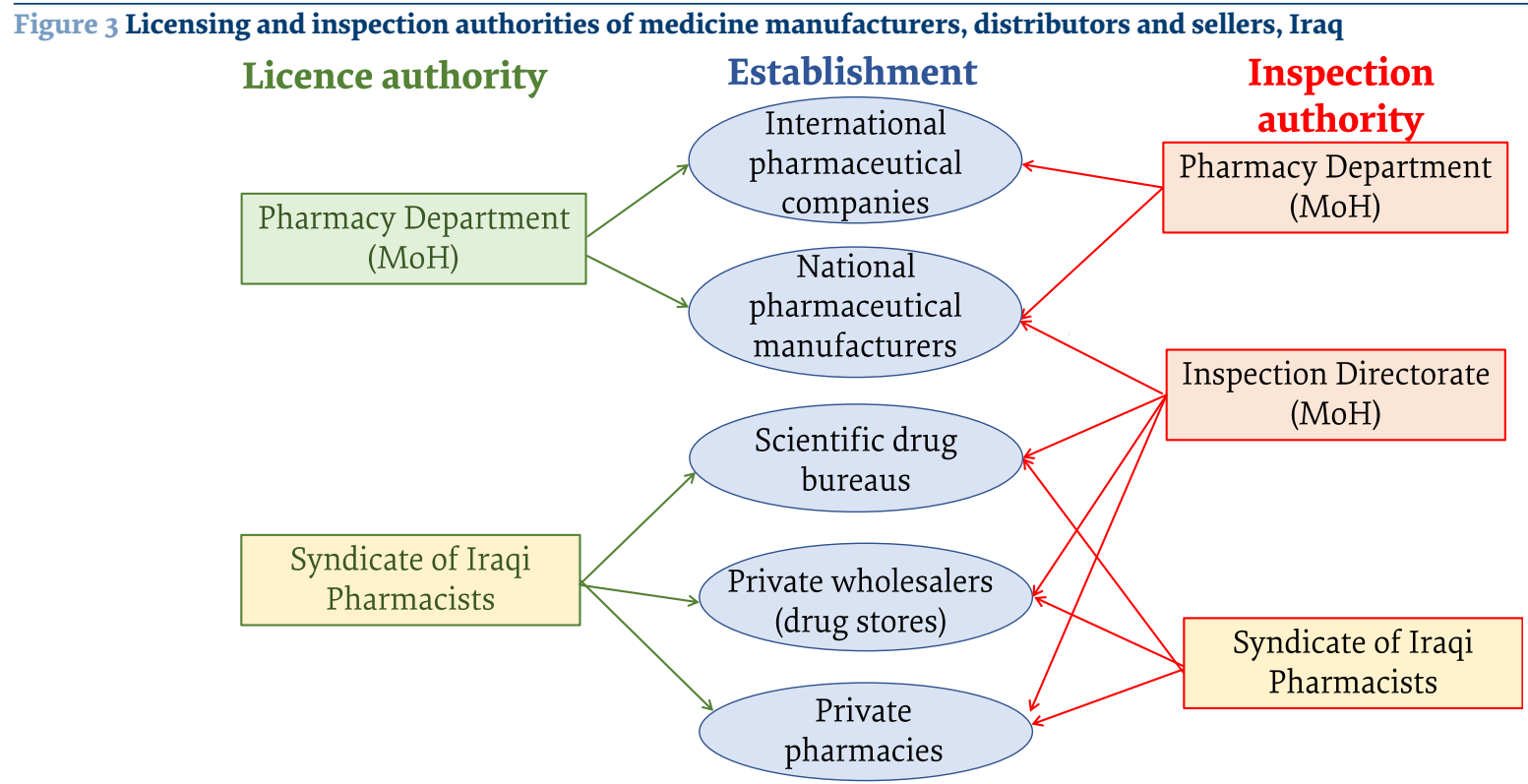

MoH: Ministry of Health.

registered medicines through scientific bureaus to drug wholesalers which in turn supply community pharmacies with medicines (Figure 2). Scientific drug bureaus are the national representatives of international pharmaceutical companies. National pharmaceutical manufacturers can provide their products directly to drug wholesalers (7). As a third party between the scientific bureaus of international companies and community pharmacies (7), drug wholesalers may increase medicine prices given that few medicines have the syndicate price sticker. In addition, wholesalers may procure substandard and/or falsified medications through unofficial routes (11).

\section{Customs policies on the pharmaceuti- cals in public and private sectors}

There are customs policies for pharmaceuticals at the federal level and in Kurdistan region, Iraq. The Customs Clearance Department of KIMADIA and the Ministry of Trade regulate pharmaceuticals at the federal level for the public and private sectors. In contrast, the Kurdistan Medicines Control Agency is responsible for regulating pharmaceuticals in Kurdistan region. The customs in Kurdistan region have a pharmacist at each point of entry, while there is no pharmacist at customs points of the federal government.

There are three main requirements for the release of medicines at customs. First, the manufacturing site must be registered (either in the federal Ministry of Health or the Kurdistan Medicines Control Agency). Second, medicines must be approved and listed in the national EML. Third, the medicines must be analysed by the quality laboratory and pass the tests successfully. There are exceptions for some medicines that have FDA and/or EMA approval which may not need to be tested.

\section{National quality control laboratory}

The National Centre for Drug Control and Research, founded in 1984, is part of the Directorate of Technical Affairs. The National Centre tests the quality of medications before registration and release to the private and public sectors (Figure 2). The National Centre usually tests the biological, chemical and physical characteristics of both imported and nationally produced medicines. The National Centre relies on pharmacopeia (US, British and European) for products in these compendia and on manufacturer-validated in-house methods for products not in the compendia (5).

The National Centre for Drug Control and Research tests medications before and after registration. Before registration, testing is part of the assessment for product registration. After registration, testing is conducted before the release of new batches (spot check). In addition, the National Centre can test medicines in case of complaints or problems identified. In contrast, there is no testing for quality monitoring in the private sector (routine sampling). Depending on the ministry department requested, the National Centre for Drug Control and Research sends the results of testing to the Registration Department, Pharmacy Department or KIMADIA. The National Centre usually examines every batch of imported and national medicines before releasing to the private market (scientific bureaus/drug wholesalers) or public health care settings. Medications with FDA, EMA and United Kingdom certificate(s) are exempted and can be released without testing or with testing one batch out of several. The National Centre has increased the total number of tested samples over the past three years: 15843 samples were tested in 2017, 17087 samples in 2018 and 19388 samples in 2019 (5). 


\section{Pharmacovigilance in Iraq}

The Iraqi Pharmacovigilance Centre assures postmarketing medication safety in private and public health care settings. The Pharmacovigilance Centre is part of the Pharmacy Department of the Directorate of Technical Affairs and has been a member the WHO International Drug Monitoring Programme since 2010 (12). The main role of the Pharmacovigilance Centre is to monitor adverse reactions to medicines, vaccines, herbal products and biopharmaceutical products in both the private and public sectors (5).

The Iraqi Pharmacovigilance Centre has a regional centre in each health care directorate which has a person responsible for hospital safety (usually a pharmacist) at each public hospital. The medication safety personnel monitors and reports any adverse drug reactions (using a paper-based form) to the regional centre, where data are processed using the Vigiflow system (a web-based individual case safety report management system) to send later to the Iraqi Pharmacovigilance Centre. In addition, companies with marketing authorization and their representatives in Iraq are required to send reports of adverse drug reactions from both public and private sectors to the Pharmacovigilance Centre (5). On the other hand, immunization is conducted in public primary health care settings and the Public Health Directorate monitors and reports adverse events following immunization to the Pharmacovigilance Centre (5). Thereafter, the Pharmacovigilance Centre validates and distributes alerts on adverse drug reactions to all public health care settings.

In addition to monitoring and providing alerts on adverse drug reactions, the Pharmacovigilance Centre has a major role in monitoring substandard and falsified medications and sending notifications about them (13). Substandard and falsified medications are usually available in the private sector only since the public sector procurement is secured by KIMADIA. In 2019, the Ministry of Health reported that $60-70 \%$ of the private sector medications were neither registered nor quality tested by the Ministry (2). According to a 2019 article in Iraq, inadequate border security measures may play a major role in substandard and falsified medications entering the private sector (11).

The scientific bureaus or pharmaceutical companies of the registered medicines usually monitor and substandard and falsified medications that are available in community pharmacies and report any to the Pharmacovigilance Centre (13). The Centre receives and distributes alerts about substandard and falsified products through the Syndicate of Iraqi Pharmacists and Directorate of Inspections (13). The Syndicate of Iraqi Pharmacists receives alerts from the Pharmacovigilance Centre and then posts them on its official website and Facebook page to inform pharmacists working in drug wholesalers and community pharmacies $(8,13)$.

When there is a claim or evidence of a problems with quality, safety or efficacy, the Pharmacovigilance Centre, in collaboration with the Inspection Directorate, has the authority to recall, suspend and withdraw medicines. Disciplinary actions that the Inspection Directorate can take include confiscation and disposal of substandard and falsified medications. It is worth noting that neither the Ministry of Health nor the private sector has an electronic tracking system to detect the locations of substandard and falsified medications inside the country. Therefore, the only way to identify these medications is through the health ministry inspections of drug wholesalers and community pharmacies and the reports from pharmaceutical company representatives or health care providers.

In 2013, the Iraqi health ministry became a member in the WHO Global Surveillance and Monitoring System for substandard and falsified medications. This is global rapid alert system to manage the threat of substandard and falsified products (14). A pharmacist in the health ministry is the focal point for the WHO Global Surveillance and Monitoring System. The focal point usually receives notifications from WHO system of substandard and falsified medications and disseminates them to public health care outlets. On 15 September 2020 , the health ministry submitted its first alert about a substandard and falsified medicine through this WHO system (5).

\section{National programme on rational use of medicines}

The unit of rational use of medicines at the clinical pharmacy section of the Pharmacy Department at the Directorate of Technical Affairs, which was established in 2008, promotes the rational use of medicines within the public health care settings (5). Clinical pharmacists who have completed the clinical pharmacy programme (run by the Clinical Pharmacy Section for 23 years) play an essential role in minimizing medications errors. They review prescribed medicines in medical charts and inform physicians about any inappropriately prescribed medicines (15).

\section{Pharmaceutical regulations in Kurdis- tan Region, Iraq}

Kurdistan Region, northern Iraq, has three provinces (Erbil, Dohuk and Sulaymaniyah) and has been autonomous since 1991. The Kurdistan Regional Government has its own Ministry of Health which collaborates with the federal Ministry of Health in Baghdad (16). The Kurdistan Medicines Control Agency (17) has its own departments to regulate pharmaceutical products in the region and has a strong collaboration with federal Directorate of Technical Affairs. All official health ministry letters and regulations are circulated from Baghdad to all public health care settings in Iraq including those in Kurdistan Region.

The Kurdistan Medicines Control Agency has a local committee for drug selection (Drug Approval Higher Committee), but it also relies on the federal selection 
committee in Baghdad to approve the medications and vaccines, and on the national EML of the federal government. Medicine prices are also regulated by the Kurdistan Medicines Control Agency (in the pricing department) and the Agency decides the price stickers of the private sector in the region.

KIMADIA (federal Ministry of Health) distributes medicines to public health care facilities in the Kurdistan region (16). The Kurdistan Medicines Control Agency does not have an agency like KIMADIA (17). Thus, local directorates of health are responsible for medicine procurement from marketing authorization holders (decentralized) in addition to the medicines from KIMADIA (centralized). The private sector in Kurdistan region relies on international pharmaceutical companies and scientific bureaus to import medications which are registered at the health ministry of the Kurdistan region. In addition, there are two local pharmaceutical industries in the region. Scientific bureaus in Baghdad can import through Kurdistan region borders. Similar to the federal health ministry, there is one quality control laboratory in the Ministry of Health of the Kurdistan region. Kurdistan does not have a pharmacovigilance department (17). Thus, it relies on the Iraqi Pharmacovigilance Centre for alerts on adverse drug reactions.

\section{Pharmaceutical-related challenges and recommendations}

Based on the last comprehensive assessment in 2020, the Iraqi pharmaceutical sector has five main challenges (5). First, all document processing and official communications within the departments of the Directorate of Technical Affairs are paper-based. In addition, all applications need in-person follow-ups by pharmaceutical company representatives. Implementing an electronic management system could help process all applications steps from drug approval to release. In addition, providing publicly available and updated information and/or instructions on the websites of the Ministry of Health departments can save pharmaceutical companies time and effort and minimize work interruptions from visits of pharmaceutical company representatives. Second, KIMADIA procured $60 \%$ of the total essential medicines in 2019. Hence, KIMADIA needs to improve its procurement procedures and the government needs to expand the allocated budget for public procurement to ensure the availability of $100 \%$ of needed essential medicines. Third, about $60-70 \%$ of medications in the private sector are neither registered nor quality tested by the Ministry of Health for various reasons. This problem can be minimized by the Ministry of Health and the private sector implementing a trace and track system. Fourth, the share of national pharmaceutical products in the national drug market is only $11 \%$ (5). Sustainable local production requires effective multisectoral collaboration to promote investment, and provide favourable legal and technical environments. National manufacturers suggest that assistance needs to be expanded beyond GMP and quality assurance standards into other key areas for regulation and policy considerations, such as help in importing active ingredients and extending the duration of importing licences (9). Finally, clear standard operating procedures should be applied in all pharmaceutical activities to minimize interference in duties between different departments and sections (5).

\section{Acknowledgement}

We thank the following people at the Iraqi Ministry of Health for providing information for this report: Ali AlBaldawi, Director-General for State Company for Marketing Drugs and Medical Appliances; Haider Hussain Motlak, Deputy Director-General for Technical Affairs Directorate; Nawfal Kareem Abdulhadi, Director of Registration Department; Ammar Sedkhan Salman, Director of Pharmacy Department; Salam Jasim, Director of National Centre for Drug Control and Research; Saba Jabir Hasson, Consulting Committees; Samir Hasson, National Centre for Drug Control and Research; Ahmed Mohammed Abdul Hameed; Director of Planning Department, State Company for Marketing Drugs and Medical Appliances; and Sarmed Amjad Rasool, Director of Importing and Distributing Medicines Department, Ministry of Health Kurdistan Region. We also thank Kawther Khalid Ahmed, University of Baghdad College of Pharmacy for drawing the report figures.

Funding: The WHO Regional Office for the Eastern Mediterranean funded the Iraq Pharmaceutical Country Profile 2020 which was the main source of this report.

Competing interests: None declared.

\section{Réglementation pharmaceutique en Iraq : de l'homologation des médicaments à la post-commercialisation}

\section{Résumé}

Contexte : Les informations récentes sur la réglementation du secteur pharmaceutique en Iraq sont rares.

Objectifs : Le présent rapport résume les réglementations régissant les produits pharmaceutiques en Iraq, évalue les défis rencontrés et formule des recommandations pour y faire face. 
Méthodes: Le profil pharmaceutique de l'Iraq pour 2020, préparé par le ministère de la Santé iraquien en collaboration avec l'Organisation mondiale de la Santé (OMS) en 2020, a été la principale source d'information.

Résultats: Malgré les nombreux efforts déployés par le ministère de la Santé pour fournir des médicaments adéquats et sûrs, le secteur pharmaceutique iraquien est confronté à plusieurs défis, notamment l'insuffisance du budget alloué au ministère, les pénuries de médicaments essentiels, une sous-utilisation des technologies électroniques dans la gestion des travaux liés à la réglementation, un grand nombre de médicaments de qualité inférieure et falsifiés dans le secteur privé et une industrie pharmaceutique nationale stagnante.

Conclusion : Le ministère de la Santé a besoin d'un soutien financier plus important de la part du gouvernement fédéral pour financer ses activités et d'un appui technique de la part d'organisations internationales œuvrant dans le domaine de la santé pour dispenser des formations et fournir des ressources.

$$
\begin{aligned}
& \text { اللوائح الصيدلانية في العراق: من الموافقة على الأدوية إلى مرحلة ما بعد التسويق }
\end{aligned}
$$

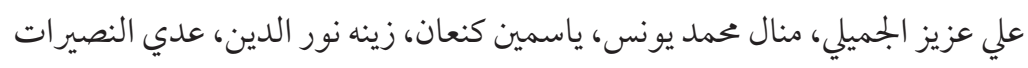

$$
\begin{aligned}
& \text { الخالاصة } \\
& \text { الخلفية: المعلومات الحديثة عن اللوائح المُنظّمة لقطاع المستحضرات الصيدلانية في العراق نادرة. } \\
& \text { الأهداف: هدف هذا التقرير الى تقديم لمحة موجزة عن اللوائح التي تحكم المنتجات الصيدلانية في العراق، وكذلك التحديات التي تواجهها، }
\end{aligned}
$$

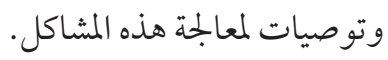

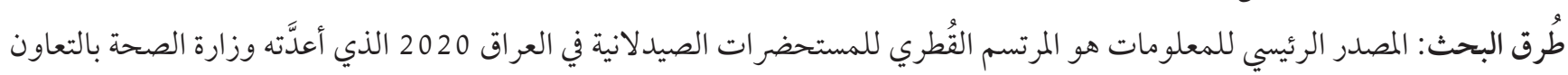

$$
\begin{aligned}
& \text { مع منظمة الصحة العالمية في ذّات السنة. }
\end{aligned}
$$

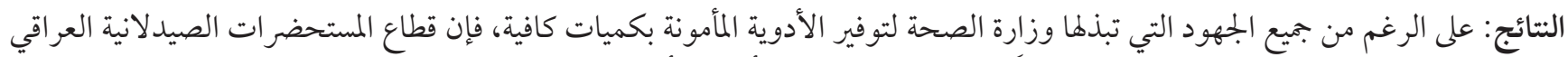

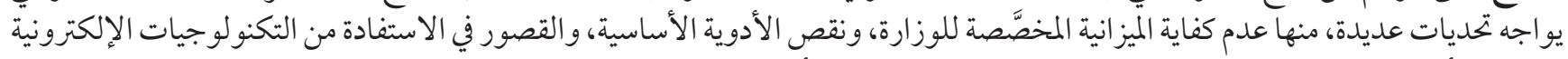

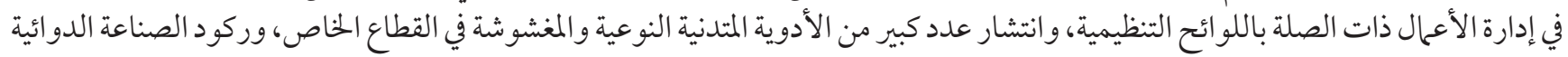

$$
\begin{aligned}
& \text { الوطنية. } \\
& \text { الاستناجات: تحتاج وزارة الصحة إلى مزيد من الدعم الملالي من الحكومة الاتحادية لتمويل أنشطتها، وإلى الدعم التقني من المنظمات الصحية الدولية }
\end{aligned}
$$

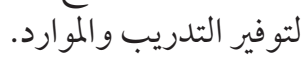

\section{References}

1. Annual statistics report 2019. Baghdad: Directorate of Planning and Resources Development, Minsitry of Health; 2020 (https:// moh.gov.iq/upload/upfile/ar/1349.pdf, accessed 17 April 2021).

2. Alwan AA. Health situation in Iraq: challenges and priorities for action. Baghdad: Ministry of Health, 2019.

3. Public Health Law no. 89 in 1981. Iraqi Parliament; 1981 (http://iraqld.hjc.iq:8080/LoadLawBook.aspx?SC=291120057072056, accessed 17 April 2021).

4. Directorate of Technical Affairs. Technical Affairs Departments [website]. Ministry of Health and Environment; 2020 (http://tecmoh.com/, accessed 17 April 2021).

5. Al-Jumaili AA. Iraq pharmaceutical country profile 2020. Baghdad: Ministry of Health, and World Health Organization; 2020 (https://moh.gov.iq/upload/upfile/ar/1375.pdf, accessed 17 April 2021).

6. Al-Kinani KK, Ibrahim MJ, Al-Zubaidi RF, Younus MM, Ramadhan SH, Kadhim HJ, et al. Iraqi regulatory authority current system and experience with biosimilars. Regul Toxicol Pharmacol. 2020;117:104768. https://doi.org/10.1016/j.yrtph.2020.104768

7. Al-Jumaili AA, Hussain SA, Sorofman B. Pharmacy in Iraq: history, current status, and future directions. Am J Health Syst Pharm. 2013;70(4):368-72. https://doi.org/10.2146/ajhp120415

8. Syndicate of Iraqi Pharmacists [website]. Syndicate of Iraqi Pharmacists 2020 (http://www.iraqipharm.com/, accessed 17 April 2021).

9. Ahmed KK, Al-Jumaili AA, Mutlak SH, Hadi MK. Determinants of national drug products acceptance across patients, pharmacists, and manufacturers: a mixed method study. J Generic Med. 2020. https://doi.org/10.1177/1741134320926625

10. The State Company For Marketing Drugs and Medical Appliances [website]. Iraq, Ministry of Health/Environment; 2020 (https://kimadia.iq/en, accessed 17 April 2021).

11. Al-Humadi A, Liapi C. Challenges of Iraq pharmaceutical market post-2003. Pharm Drug Regul Affair J. 2019;2(2):000116. 
12. Alwan MH. Guidelines for detecting \& reporting adverse drug reactions In Iraq. Individual case safety report. Baghdad: Iraqi Pharmacovigilance Center (IPhvC); 2012 (https://www.who-umc.org/media/1078/iraq.pdf, accessed 17 April 2021).

13. Al-Jumaili AA, Younus MM, Saleh MZ. The Epidemic of Substandard and Falsified Medications in Iraq: Evaluating the Effectiveness of National Pharmacovigilance Alerts to Community Pharmacies. Pharmaceutical medicine. 2021. DOI: 10.1007/s40290-02100386-9

14. WHO Global surveillance and monitoring system. Geneva: World Health Organization; 2013 (https://www.who.int/medicines/ regulation/ssffc/surveillance/en/, accessed 17 April 2021).

15. Al-Jumaili AA, Jabri AM, Al-Rekabi MD, Abbood SK, Hussein AH. Physician acceptance of pharmacist recommendations about medication prescribing errors in Iraqi hospitals. Innov Pharm, 2016;7(3).

16. Ministry of Health [website]. Kurdistan Regional Government; 2021 (https://gov.krd/moh-en/, accessed 17 April 2021).

17. Kurdistan Medical Control Agency [website]. Kurdistan Regional Government; 2021 (https://www.kmcakrg.org/, accessed 17 April 2021). 